\title{
Association between Helicobacter pylori infection and angiographically demonstrated coronary artery disease: A meta-analysis
}

\author{
XIN-JUAN YU ${ }^{1}$, XUAN YANG $^{2}$, LEI FENG ${ }^{3}$, LI-LI WANG ${ }^{1}$ and QUAN-JIANG DONG ${ }^{1}$ \\ ${ }^{1}$ Central Laboratories; Departments of ${ }^{2}$ Cardiology and ${ }^{3}$ Radiology, \\ Qingdao Municipal Hospital, Qingdao, Shandong 266000, P.R. China
}

Received October 11, 2015; Accepted November 04, 2016

DOI: $10.3892 /$ etm.2017.4028

\begin{abstract}
Coronary artery disease (CAD) is a leading cause of mortality globally. However, the etiology and pathogenesis of CAD are not fully understood. The aim of the present meta-analysis was to estimate the association between the risk of CAD and Helicobacter pylori $(H$. pylori) infection. A literature search was performed to identify eligible studies published prior to August 14, 2014. Fixed or random effect meta-analytical methods were used to pool the data and perform the subgroup analyses. The effect measures estimated were the odds ratios (OR) for dichotomous data reported with $95 \%$ confidence intervals $(95 \% \mathrm{CI})$. Of the 109 studies identified using the search parameters, 26 cross-sectional studies were eligible involving 3,901 CAD patients and 2,751 controls. $H$. pylori infection was associated with an increased risk of CAD (OR: 1.96, 95\% CI: 1.47-2.63, P<0.00001). When the adjusted ORs were used to conduct another meta-analysis, the OR value decreased, but the association remained significant (OR: 1.42, 95\% CI: 1.09-1.86, $\mathrm{P}=0.008)$. The association between $H$. pylori infection and CAD risk was stronger in younger individuals than in older individuals (OR: 2.36, 95\% CI 1.50-3.73 vs. OR: $1.59,95 \%$ CI: 1.19-2.11). A significant association was observed in studies from Europe (OR: 2.11, 95\% CI: 1.54-2.88, $\mathrm{P}=0.01$ ) and the USA (OR: 1.43, 95\% CI: 1.08-1.91, $\mathrm{P}=0.36$ ). There is a potential association between $H$. pylori infection and the risk of CAD. The association may be influenced by age and ethnicity.
\end{abstract}

\section{Introduction}

Coronary artery disease (CAD), also known as ischemic heart disease (IHD), atherosclerotic heart disease, atherosclerotic

Correspondence to: Dr Quan-Jiang Dong, Central Laboratories, Qingdao Municipal Hospital, 18 Zhuhai Road, Shinan, Qingdao, Shandong 266000, P.R. China

E-mail: jiangacer@126.com

Key words: Helicobacter pylori, coronary artery disease, meta-analysis, subgroup analysis cardiovascular disease and coronary heart disease, is a leading cause of mortality globally. It is reported to have caused 7.4 million mortalities (13.2\% of all deaths) in 2012 worldwide (1). The etiology and pathogenesis of CAD are not fully understood. The common risk factors, including hypertension, diabetes mellitus, smoking, obesity, serum lipids, family history and socioeconomic status, do not fully account for all cases (2). Chronic infections, including Helicobacter pylori (H. pylori) infection, are assumed to play a role in the pathogenesis of CAD (3).

H. pylori is a gram-negative bacterium infecting more than half the world's population (4). The infection results in chronic gastritis, peptic ulcer disease and gastric cancer (5). It is also associated with extra-gastrointestinal conditions, including diabetes mellitus and stroke $(6,7)$. Previous studies have focused on the association between $H$. pylori infection and the risk of CAD. However, the role of $H$. pylori in CAD remains unclear $(8,9)$.

Studies in which the potential association between H. pylori infection and CAD has been investigated have shown conflicting results. In the majority of studies, CAD was diagnosed using clinical questionnaires or on the basis of abnormalities on electrocardiograms. As patients with other diseases may also present with chest pain syndromes similar to CAD, these diagnostic methods would result in high confounding bias. Coronary angiography is a sensitive and specific technique for diagnosing CAD. It is considered to be a 'gold standard' for the diagnosis of CAD (10). Therefore, the present meta-analysis was conducted to determine the association between $H$. pylori infection and CAD risk. The data were obtained from studies in which CAD was diagnosed by coronary angiography to obtain a more comprehensive estimate of the putative influence of $H$. pylori on CAD.

\section{Materials and methods}

Data search. Studies were selected on the basis of a structured literature search in PubMed, EMBASE and the Cochrane library. Search terms were 'coronary artery disease [All Fields]' OR 'coronary heart disease [All Fields]' OR 'coronary atherosclerosis [All Fields]' OR 'myocardial infarction [All Fields]' OR 'angina [All Fields]' OR 'atheroma [All Fields]' 
OR 'ischemic heart disease [All Fields]' OR 'ischaemic heart disease [All Fields]' AND 'Helicobacter pylori [All Fields]' AND 'angiography [All Fields]'. The references in the articles were checked, and suitable studies identified from them were also used. The date of the most recent search was August 14, 2014.

Data selection. All selections were performed in duplicate. The final inclusion of studies was determined by consensus, and when this failed, a third author adjudicated. The following inclusion criteria were used: i) Studies that compared the incidence of angiographically demonstrated CAD in $H$.pylori infected subjects and uninfected subjects; and ii) studies that compared the incidence of $H$. pylori infection in angiographically demonstrated CAD patients and non-CAD controls. Studies that did not meet these inclusion criteria were excluded. Articles not in the English language were also excluded.

Data extraction. Two trained research personnel independently extracted the following data: First author, country, year of publication, mean age of patients, study size, study type, methods of $H$.pylori detection, matched variables and adjusted variables. All data were double-entered.

Statistical analysis. The meta-analysis was performed using Review Manager (RevMan) version 5.3 (The Cochrane Collaboration, Oxford, UK). The effect measures estimated were the odds ratio (OR) and relative risk (RR) for dichotomous data reported with $95 \%$ confidence intervals (95\% CIs). An OR/RR was considered statistically significant if the $95 \%$ CI did not include the value 1 . An analysis of the heterogeneity of the studies was performed using the $\chi^{2}$-based $\mathrm{Q}$ test. $\mathrm{P}<0.1$ and $\mathrm{I}^{2}>50 \%$ were considered significant for heterogeneity. If the studies were shown to be homogeneous with $\mathrm{P}>0.1$, a fixed-effects model (the Mantel-Haenszel method) was used, otherwise, the random-effects model (the DerSimonian and Laird method) was used. The potential publication bias was assessed with funnel plots. A sensitivity analysis was carried out to assess heterogeneity. Each study was sequentially removed from the analysis to determine its contribution to the overall effect size. All studies were scored using the modified Newcastle-Ottawa Scale system (11). This scoring system evaluated studies based on patient selection, comparability of the groups, and assessment of outcome. When an article received a score of $>6$ in this scoring system, it was regarded as a high-quality article.

\section{Results}

Eligible studies. Of the 109 studies identified, 26 studies (12-37) were eligible. The reasons why other studies did not meet the inclusion criteria were as follows: They were reviews, comments, news, case reports or letters with no original data $(\mathrm{n}=18)$; non-English articles $(\mathrm{n}=4)$; studies of other topics $(\mathrm{n}=54)$; the full text could not be found $(\mathrm{n}=1)$; and studies on this topic, but did not use coronary angiography to diagnose CAD $(n=6)$. A manual search of the listed references revealed no further studies. Of these 26 studies, 24 compared the incidence of $H$. pylori infection in angiographically diagnosed CAD patients and non-CAD controls, while only two studies [Lee et al (22) and Zhu et al (25) ], involving <500 participants, compared the incidence of CAD in $H$. pylori infected subjects and uninfected subjects. A meta-analysis could not be conducted for these studies. The two studies also compared the incidence of $H$. pylori infection in CAD patients and non-CAD controls. Therefore, they were analyzed together with the other 24 studies. The characteristics of the selected studies are summarized in Table I.

H. pylori infection and CAD risk. Of these 26 studies, 13 indicated that $H$. pylori infection was associated with a higher risk of CAD, while the others showed no association. The total number of CAD patients was 3,901, and that of non-CAD controls was 2,751. The H. pylori positive rate in CAD patients and controls was $61.3 \%(2,390 / 3,901)$ and $42.5 \%(1,168 / 2,751)$, respectively. The random effect pooled OR was 1.96 (95\% CI: 1.47-2.63, $\mathrm{P}<0.00001$; Fig. 1). When excluding 12 studies that had a low score $(\leq 6), 14$ studies remained. Meta-analysis showed that the random effect pooled OR was 1.75 (95\% CI: $1.39-2.19, \mathrm{P}=0.008)$. The studies with high scores $(\geq 7)$ had adjusted some variables associated with CAD. The adjusted ORs were used to conduct another meta-analysis. The random effect pooled OR was 1.42 (95\% CI: 1.09-1.86, P=0.008; Fig. 2). The adjusted effect pooled OR was lower than the unadjusted, but the association was still significant.

Subgroup analysis. To investigate the influencing factors of heterogeneity, the data were further stratified according to the year of publication, methods of $H$. pylori detection, and whether matched for gender, mean age, socioeconomic level and geographical region. Subgroup analyses according to the above factors were then conducted. The results are shown in Table II. The association between $H$. pylori infection and CAD risk was stronger in younger individuals (those $<60$ years old) than in older individuals (OR: $2.36,95 \%$ CI: $1.50-3.73$ vs. OR: $1.59,95 \%$ CI: 1.19-2.11). A significant association was observed in studies from Europe (OR: 2.11, 95\% CI: 1.54-2.88, $\mathrm{P}=0.01$ ) and the USA (OR: 1.43, 95\% CI: 1.08-1.91, $\mathrm{P}=0.36$ ).

Sensitivity analysis and publication bias. A sensitivity analysis was performed to assess the influence of each individual study on the pooled ORs by omitting a single study each time. The results showed that there was no substantial change in the corresponding pooled OR. Publication bias was assessed using funnel plots. In the funnel plots, the largest studies were near the average, small studies were spread on both sides of the average and an asymmetric inverted funnel shape was obtained (Fig. 3). Therefore, funnel plots showed no evidence of significant publication bias in the meta-analyses.

\section{Discussion}

The studies included in the meta-analysis applied strict diagnostic criteria for CAD diagnosis, and the results were more reliable than those of a previous meta-analysis (38). All included studies during quality assessment achieved satisfactory scores $(\geq 6)$. The meta-analysis including the high quality studies (scores $\geq 7$ ) did not significantly change the pooled OR. Sensitivity analysis did not demonstrate that any single study would lead to a statistically significant effect size in the meta-analysis. Therefore, the included studies showed good 


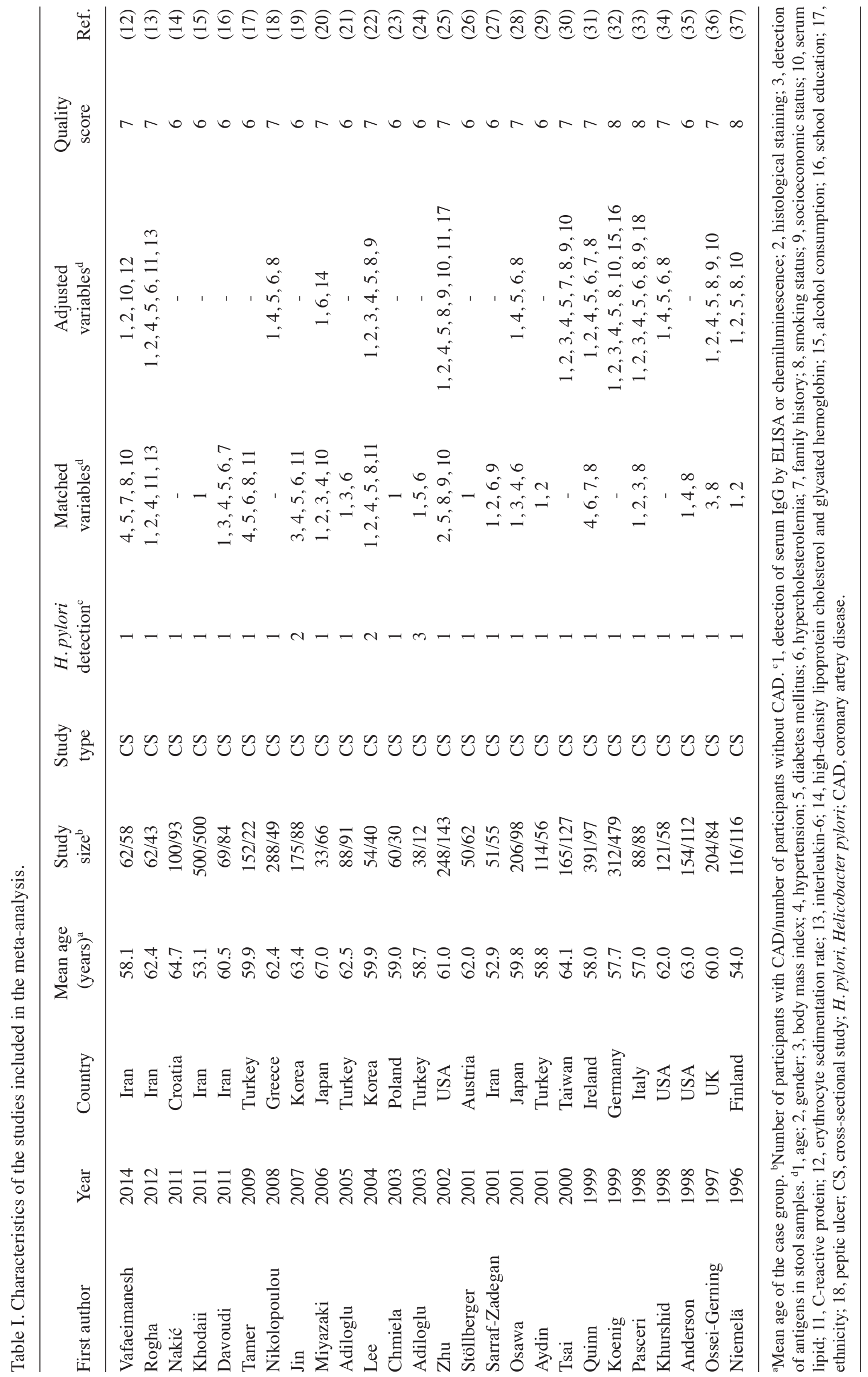




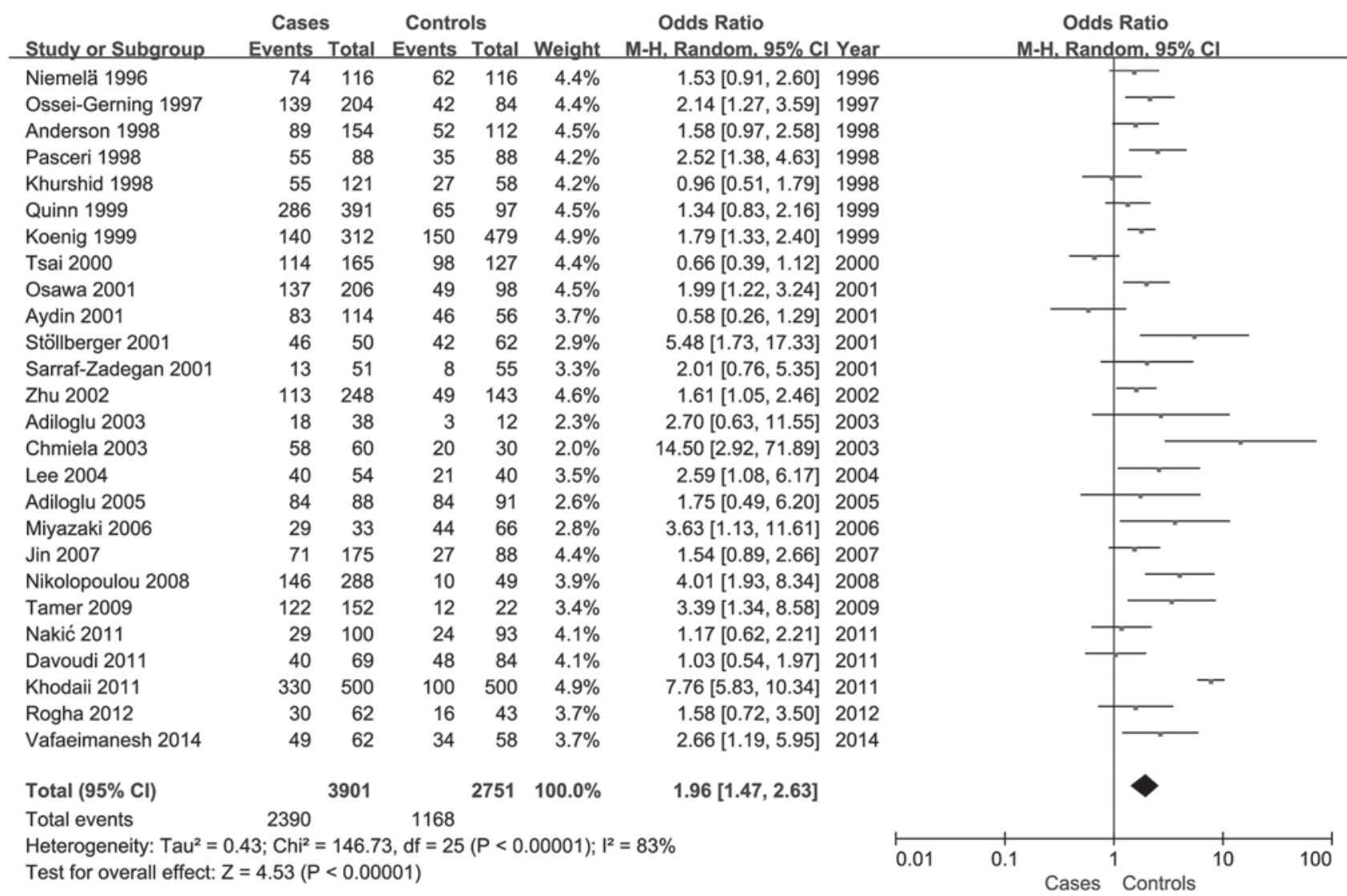

Figure 1. Random-effect meta-analysis of the studies evaluating Helicobacter pylori infection and CAD risk. The squares indicate point estimates of pathogenic effect, with the size of the square representing the weight attributed to each study, and $95 \%$ CIs are indicated by horizontal bars. The diamond represents the summary OR from the pooled studies with 95\% CI; cases represents CAD patients; controls represents non-CAD subjects; events represents the number of subjects with $\mathrm{H}$. pylori infection in each group and total represents the total number of subjects in each group. CAD, coronary artery disease; CI, confidence interval; OR, odds ratio.

\begin{tabular}{|c|c|c|c|c|c|c|c|c|c|c|c|}
\hline Study or subgroup & log[Odds ratio] & SE & Weight & $\begin{array}{c}\text { Odds ratio } \\
\text { IV, Random, } 95 \% \mathrm{Cl}\end{array}$ & Year & & & $\begin{array}{r}\text { Odds } \\
\text { IV. Rando }\end{array}$ & $\begin{array}{l}\text { ratio } \\
\mathrm{m} .95 \% \mathrm{Cl}\end{array}$ & & \\
\hline Niemela 1996 & 0.0953 & 0.3093 & $8.7 \%$ & $1.10[0.60,2.02]$ & 1996 & & & & & & \\
\hline Ossei-Gerning 1997 & 0.8879 & 0.3773 & $7.1 \%$ & $2.43[1.16,5.09]$ & 1997 & & & & & & \\
\hline Khurshid 1998 & -0.7985 & 0.5605 & $4.3 \%$ & $0.45[0.15,1.35]$ & 1998 & & & & & & \\
\hline Pasceri 1998 & 1.0296 & 0.3915 & $6.9 \%$ & $2.80[1.30,6.03]$ & 1998 & & & & & & \\
\hline Koenig 1999 & 0.2624 & 0.1876 & $12.1 \%$ & $1.30[0.90,1.88]$ & 1999 & & & & $=$ & & \\
\hline Quinn 1999 & 0.1906 & 0.3093 & $8.7 \%$ & $1.21[0.66,2.22]$ & 1999 & & & & $=$ & & \\
\hline Tsai 2000 & -0.5276 & 0.5276 & $4.7 \%$ & $0.59[0.21,1.66]$ & 2000 & & & & - & & \\
\hline Osawa 2001 & 0.3001 & 0.138 & $13.5 \%$ & $1.35[1.03,1.77]$ & 2001 & & & & - & & \\
\hline Zhu 2002 & 0.0296 & 0.2757 & $9.6 \%$ & $1.03[0.60,1.77]$ & 2002 & & & & - & & \\
\hline Lee 2004 & -0.844 & 0.5725 & $4.2 \%$ & $0.43[0.14,1.32]$ & 2004 & & & & & & \\
\hline Miyazaki 2006 & 1.4085 & 0.67 & $3.3 \%$ & $4.09[1.10,15.21]$ & 2006 & & & & & & \\
\hline Nikolopoulou 2008 & 0.6387 & 0.3701 & $7.3 \%$ & $1.89[0.92,3.91]$ & 2008 & & & & & & \\
\hline Rogha 2012 & 1.1569 & 0.551 & $4.4 \%$ & $3.18[1.08,9.36]$ & 2012 & & & & & & \\
\hline Vafaeimanesh 2014 & 1.3507 & 0.4891 & $5.2 \%$ & $3.86[1.48,10.07]$ & 2014 & & & & & & \\
\hline Total $(95 \% \mathrm{Cl})$ & & & $100.0 \%$ & $1.42[1.09,1.86]$ & & & & & & & \\
\hline \multicolumn{6}{|c|}{$\begin{array}{l}\text { Heterogeneity: } \mathrm{Tau}^{2}=0.12 ; \mathrm{Chi}^{2}=28.30, d \\
\text { Test for overall effect: } Z=2.59(P=0.010)\end{array}$} & 0.01 & 0.1 & 1 & 1 & 10 & 100 \\
\hline
\end{tabular}

Figure 2. Random-effect meta-analysis of the studies adjusted for potential confounders in which Helicobacter pylori infection and coronary artery disease risk are evaluated. The squares indicate point estimates of pathogenic effect, with the size of the square representing the weight attributed to each study, and 95\% CIs are indicated by horizontal bars. The diamond represents the summary OR from the pooled studies with $95 \%$ CI. $\log [$ Odds ratio], logarithm of the adjusted OR; SE, standard error of the adjusted OR; CI, confidence interval; OR, odds ratio.

homogeneity. During the graphical exploration with funnel plots, no evidence of significant publication bias was found, indicating that the results of these meta-analyses were reliable.
The results showed that the risk of CAD increased $\sim 2$-fold in patients with $H$. pylori infection. However, when some variables associated with CAD were adjusted, the risk decreased 
Table II. Results of the meta-analyses in the subgroups.

\begin{tabular}{|c|c|c|c|c|}
\hline Subgroup & No. of studies (study size ${ }^{a}$ ) & P-value ${ }^{b}$ & $\mathrm{I} 2^{\mathrm{c}}(\%)$ & OR $(95 \% \mathrm{CI})$ \\
\hline \multicolumn{5}{|l|}{ Year of publication } \\
\hline Before 2000 & $7(1,386 / 1,034)$ & 0.34 & 12 & $1.66(1.40-1.98)$ \\
\hline During or after 2000 & $19(2,515 / 1,717)$ & $<0.00001$ & 86 & $2.17(1.42-3.31)$ \\
\hline \multicolumn{5}{|l|}{ H. pylori detection } \\
\hline Serum IgG & $23(3,634 / 2,611)$ & $<0.00001$ & 85 & $1.96(1.42-2.69)$ \\
\hline Histological staining & $2(229 / 128)$ & 0.32 & 0 & $1.78(1.12-2.82)$ \\
\hline \multicolumn{5}{|l|}{ Matched for gender } \\
\hline Matched & $8(766 / 607)$ & 0.12 & 39 & $1.68(1.34-2.12)$ \\
\hline Not matched & $18(3,135 / 2,144)$ & $<0.00001$ & 87 & $2.08(1.42-3.06)$ \\
\hline \multicolumn{5}{|l|}{ Mean age (years) } \\
\hline$<60$ & $13(2,144 / 1,651)$ & $<0.00001$ & 87 & $2.36(1.50-3.73)$ \\
\hline$\geq 60$ & $13(1,757 / 1,100)$ & 0.004 & 59 & $1.59(1.19-2.11)$ \\
\hline \multicolumn{5}{|l|}{ Socioeconomic level } \\
\hline Developed countries & $15(2,605 / 1,707)$ & 0.005 & 55 & $1.75(1.41-2.17)$ \\
\hline Developing countries & $11(1,296 / 1,044)$ & $<0.00001$ & 88 & $2.23(1.15-4.32)$ \\
\hline \multicolumn{5}{|l|}{ Geographical region } \\
\hline Europe & $9(1,609 / 1,098)$ & 0.01 & 59 & $2.11(1.54-2.88)$ \\
\hline Middle East & $9(1,136 / 921)$ & $<0.00001$ & 88 & $2.07(0.99-4.30)$ \\
\hline East Asia & $5(633 / 419)$ & 0.007 & 72 & $1.64(0.94-2.85)$ \\
\hline USA & $3(523 / 313)$ & 0.36 & 1 & $1.43(1.08-1.91)$ \\
\hline
\end{tabular}

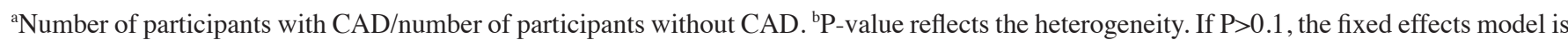
reported; otherwise, the random effects model is reported. ' ${ }^{2}{ }^{2}$ is used to quantify heterogeneity. If $\mathrm{I}^{2}>50 \%$, there may be obvious heterogeneity, and the random effects model is reported; otherwise, the fixed effects model is reported. CAD, coronary artery disease.

A

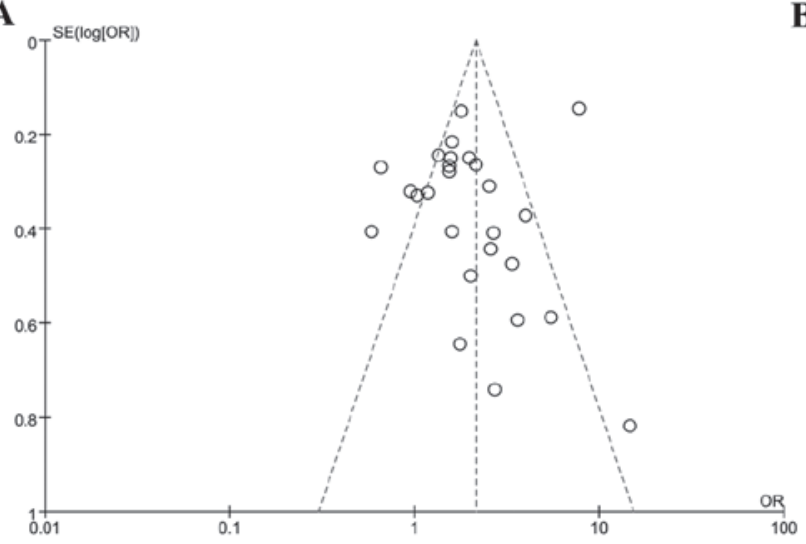

B

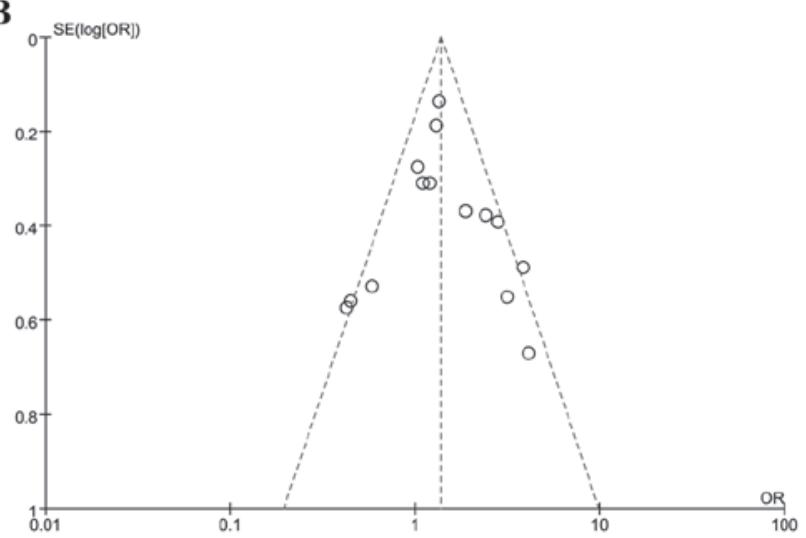

Figure 3. Funnel plots of studies evaluating Helicobacter pylori infection and coronary artery disease risk. (A) All studies and (B) studies with adjusted confounding variables. SE (log [OR]), standard error of the logarithm of the odds ratio.

to 1.42 -fold. This indicated that H. pylori infection was a potential independent risk factor for $\mathrm{CAD}$, and may play a role in the pathogenesis of CAD.

Year of publication and $H$. pylori diagnostic method could affect homogeneity. Age, gender, ethnicity and socioeconomic level were associated with both $H$. pylori infection and CAD risk. Therefore, subgroup analyses according to the above factors were performed. During the subgroup analysis, the year of publication, $H$. pylori diagnostic method, gender and socioeconomic level did not influence the reliability of the results. However, the results indicated that the association between CAD risk and H. pylori infection was age- and ethnicity-dependent. The association was stronger in younger individuals than in older individuals. These results were consistent with those of previous studies, which demonstrated that the effect of most cardiovascular risk factors on cardiovascular diseases was stronger in younger than in older individuals $(39,40)$. The effect of $H$. pylori infection on CAD 
was stronger in Caucasians in this meta-analysis. It is generally acknowledged that the prevalence of $H$. pylori infection in younger individuals and Caucasians is lower than that in older individuals and other ethnicities. Therefore, $H$. pylori infection appears to have a greater impact on CAD risk in low prevalence populations.

This meta-analysis demonstrated that $H$.pylori infection was associated with the risk of CAD. CAD and $H$. pylori infection could potentially share common factors of genetic susceptibility. Genetic loci associated with host susceptibility to CAD or H.pylori infection have been identified using genome-wide association studies (GWAS) in recent years (41-46). GWAS represent an essentially unbiased approach capable of simultaneously assessing thousands of genetic variants across the whole genome for association with CAD or H.pylori infection. To date, multiple GWAS have identified >50 common genetic susceptibility loci independently associated with CAD (41-44). Two studies identified four single nucleotide polymorphisms (SNPs: rs4833095, rs10004195, rs368433 and rs10502974) located in different genes that were associated with $H$. pylori infection using GWAS $(45,46)$. However, no genetic locus associated with both $H$. pylori infection and CAD risk has been found. Therefore, there is no good evidence to demonstrate that CAD and H. pylori infection share common factors of genetic susceptibility. H. pylori infection increases the risk of CAD and this may be due to the pathogenicity of $H$. pylori.

$H$. pylori infection can affect CAD risk in various ways. Two studies found $H$. pylori DNA in the aortic tissues and atherosclerotic plaques of patients with CAD $(47,48)$. This may be an important indication of the direct role of $H$. pylori in the pathogenesis of CAD. Chronic H. pylori infection can reduce serum high-density lipoprotein (HDL) cholesterol and apolipoprotein-A, but elevate total cholesterol, low-density lipoprotein (LDL) cholesterol, triglyceride and apolipoprotein-B levels (49). These alterations in lipid profiles may promote the atherosclerotic process. Chronic $H$. pylori infection triggers the release of inflammatory cytokines and coagulation factors such as interleukin (IL)-1, IL-6, IL-8, tumor necrosis factor- $\alpha$, fibrinogen and prothrombin fragments, resulting in vasoconstriction, endothelial dysfunction and slowed flow in the major epicardial coronary arteries (50). These factors link $H$. pylori infection to the development of CAD.

In conclusion, this meta-analysis demonstrated a potential association between $H$. pylori infection and the risk of CAD. The association may be influenced by age and ethnicity. More research is required to explore the mechanisms involved.

\section{References}

1. World Health Organization: The top 10 causes of death. http://www.who.int/mediacentre/factsheets/fs310/en/. Accessed August 14, 2014.

2. Helfand M, Buckley DI, Freeman M, Fu R, Rogers K, Fleming C and Humphrey LL: Emerging risk factors for coronary heart disease: A summary of systematic reviews conducted for the U.S. preventive services task force. Ann Intern Med 151: 496-507, 2009.

3. Kowalski M, Pawlik M, Konturek JW and Konturek SJ: Helicobacter pylori infection in coronary artery disease. J Physiol Pharmacol 57 (Suppl 3): 101-111, 2006.

4. Yu M, Zhang Y, Yang Z, Ding J, Xie C and Lu N: Association between Helicobacter pylori infection and stroke: A meta-analysis of prospective observational studies. J Stroke Cerebrovasc Dis 23: 2233-2239, 2014.
5. Watari J, Chen N, Amenta PS, Fukui H, Oshima T, Tomita T, Miwa H, Lim KJ and Das KM: Helicobacter pylori associated chronic gastritis, clinical syndromes, precancerous lesions, and pathogenesis of gastric cancer development. World J Gastroenterol 20: 5461-5473, 2014

6. Wang F, Liu J and Lv Z: Association of Helicobacter pylori infection with diabetes mellitus and diabetic nephropathy: A meta-analysis of 39 studies involving more than 20,000 participants. Scand J Infect Dis 45: 930-938, 2013.

7. Grau AJ, Urbanek C and Palm F: Common infections and the risk of stroke. Nat Rev Neurol 6: 681-694, 2010.

8. Kanbay M, Gür G, Yucel M, Yilmaz U and Muderrisoglu H: Helicobacter pylori seroprevalence in patients with coronary artery disease. Dig Dis Sci 50: 2071-2074, 2005.

9. Vcev A, Nakić D, Mrden A, Mirat J, Balen S, Ruzić A, Persić V, Soldo I, Matijević M, Barbić J, et al: Helicobacter pylori infection and coronary artery disease. Coll Antropol 31: 757-760, 2007.

10. Montalescot G, Sechtem U, Achenbach S, Achenbach S, Andreotti F, Arden C, Budaj A, Bugiardini R, Crea F, Cuisset T, et al: 2013 ESC guidelines on the management of stable coronary artery disease: The task force on the management of stable coronary artery disease of the European society of cardiology. Eur Heart J 34: 2949-3003, 2013.

11. Athanasiou T, Al-Ruzzeh S, Kumar P, Crossman MC, Amrani M, Pepper JR, Del Stanbridge R, Casula R and Glenville B: Off-pump myocardial revascularization is associated with less incidence of stroke in elderly patients. Ann Thorac Surg 77: 745-753, 2004

12. Vafaeimanesh J, Hejazi SF, Damanpak V, Vahedian M, Sattari M and Seyyedmajidi M: Association of Helicobacter pylori infection with coronary artery disease: Is Helicobacter pylori a risk factor? ScientificWorld Journal 2014: 516354, 2014.

13. Rogha M, Nikvarz M, Pourmoghaddas Z, Shirneshan K, Dadkhah D and Pourmoghaddas M: Is helicobacter pylori infection a risk factor for coronary heart disease? ARYA Atheroscler 8 : $5-8,2012$

14. Nakić D, Vcev A, Jović A, Patrk J, Zekanović D, Klarin I, Ivanac K, Mrden A and Balen S: Helicobacter pylori infection and acute myocardial infarction. Coll Antropol 35: 781-785, 2011.

15. Khodaii Z, Vakili H, Ghaderian SM, Najar RA and Panah AS: Association of Helicobacter pylori infection with acute myocardial infarction. Coron Artery Dis 22: 6-11, 2011.

16. Davoudi S, Omran SA, Mohammad AB, Rahimian N and Saadat S: Association between Helicobacter pylori and coronary artery disease. Cent Eur J Med 6: 107-112, 2011.

17. Tamer GS, Tengiz I, Ercan E, Duman C, Alioglu E and Turk UO: Helicobacter pylori seropositivity in patients with acute coronary syndromes. Dig Dis Sci 54: 1253-1256, 2009.

18. Nikolopoulou A, Tousoulis D, Antoniades C, Petroheilou K, Vasiliadou C, Papageorgiou N, Koniari K, Stefanadi E, Latsios G, Siasos G and Stefanadis C: Common community infections and the risk for coronary artery disease and acute myocardial infarction: Evidence for chronic over-expression of tumor necrosis factor alpha and vascular cells adhesion molecule-1. Int J Cardiol 130: 246-250, 2008.

19. Jin SW, Her SH, Lee JM, Yoon HJ, Moon SJ, Kim PJ, Baek SH, Seung KB, Kim JH, Kang SB, et al: The association between current Helicobacter pylori infection and coronary artery disease. Korean J Intern Med 22: 152-156, 2007.

20. Miyazaki M, Babazono A, Kadowaki K, Kato M, Takata T and Une H: Is Helicobacter pylori infection a risk factor for acute coronary syndromes? J Infect 52: 86-91, 2006.

21. Adiloglu AK, Can R, Nazli C, Ocal A, Ergene O, Tinaz G and Kisioglu N: Ectasia and severe atherosclerosis: Relationships with chlamydia pneumoniae, helicobacter pylori, and inflammatory markers. Tex Heart Inst J 32: 21-27, 2005.

22. Lee SY, Kim DK, Son HJ, Lee JH, Kim YH, Kim JJ, Paik SW and Rhee JC: The impact of Helicobacter pylori infection on coronary heart disease in a Korean population. Korean J Gastroenterol 44: 193-198, 2004.

23. Chmiela M, Kowalewicz-Kulbat M, Miszczak A, Wisniewska M, Rechcinski T, Kolodziej K, Kasprzak J, Wadstrom T and Rudnicka W: A link between Helicobacter pylori and/or Chlamydia spp. infections and atherosclerosis. FEMS Immunol Med Microbiol 36: 187-192, 2003.

24. Adiloglu AK, Nazli C, Cicioglu-Aridogan B, Kinay O, Can R and Ergene O: Gastroduodenal Helicobacter pylori infection diagnosed by Helicobacter pylori stool antigen is related to atherosclerosis. Acta Cardiol 58: 335-339, 2003. 
25. Zhu J, Quyyumi AA, Muhlestein JB, Nieto FJ, Horne BD Zalles-Ganley A, Anderson JL and Epstein SE: Lack of association of Helicobacter pylori infection with coronary artery disease and frequency of acute myocardial infarction or death Am J Cardiol 89: 155-158, 2002.

26. Stöllberger C, Mölzer G and Finsterer J: Seroprevalence of antibodies to microorganisms known to cause arterial and myocardial damage in patients with or without coronary stenosis. Clin Diagn Lab Immunol 8: 997-1002, 2001.

27. Sarraf-Zadegan N, Amiri M and Maghsoudloo S: Helicobacter pylori relation to acute myocardial infarction in an Iranian sample. Coronary Health Care 5: 202-207, 2001.

28. Osawa H, Kawakami M, Fujii M, Kubo N, Iwanaka H, Yamamoto W, Saitoh M, Yaginuma T and Sugano K: Helicobacter pylori infection and coronary heart disease in Japanese patients. Cardiology 95: 14-19, 2001.

29. Aydin A, Vardar R, Evrengul H, Ungan M, Yilmaz M and Payzin S: Does Helicobacter pylori infection have a role in coronary artery disease? Turk J Gastroenterol 12: 287-293, 2001

30. Tsai CJ and Huang TY: Relation of Helicobacter pylori infection and angiographically demonstrated coronary artery disease. Dig Dis Sci 45: 1227-1232, 2000.

31. Quinn MJ, Foley JB, Mulvihill NT, Lee J, Crean PA, Walsh MJ and O'Morain CA: Helicobacter pylori serology in patients with angiographically documented coronary artery disease. Am J Cardiol 83: 1664-1666, A6, 1999.

32. Koenig W, Rothenbacher D, Hoffmeister A, Miller M, Bode G, Adler G, Hombach V, März W, Pepys MB and Brenner H: Infection with Helicobacter pylori is not a major independent risk factor for stable coronary heart disease: Lack of a role of cytotoxin- associated protein A-positive strains and absence of a systemic inflammatory response. Circulation 100: 2326-2331, 1999.

33. Pasceri V, Cammarota G, Patti G, Cuoco L, Gasbarrini A Grillo RL, Fedeli G, Gasbarrini G and Maseri A: Association of virulent Helicobacter pylori strains with ischemic heart disease. Circulation 97: 1675-1679, 1998.

34. Khurshid A, Fenske T, Bajwa T, Bourgeois K and Vakil N: A prospective, controlled study of Helicobacter pylori seroprevalence in coronary artery disease. Am J Gastroenterol 93: 717-720, 1998.

35. Anderson JL, Carlquist JF, Muhlestein JB, Horne BD and Elmer SP: Evaluation of C-reactive protein, an inflammatory marker and infectious serology as risk factors for coronary artery disease and myocardial infarction. J Am Coll Cardiol 32: 35-41, 1998.

36. Ossei-Gerning N, Moayyedi P, Smith S, Braunholtz D, Wilson JI, Axon AT and Grant PJ: Helicobacter pylori infection is related to atheroma in patients undergoing coronary angiography. Cardiovasc Res 35: 120-124, 1997.

37. Niemelä S, Karttunen T, Korhonen T, Läärä E, Karttunen R, Ikäheimo $\mathrm{M}$ and Kesäniemi YA: Could Helicobacter pylori infection increase the risk of coronary heart disease by modifying serum lipid concentrations? Heart 75: 573-575, 1996.
38. Pellicano R, Mladenova I, Broutet N, Salmi LR and Mégraud F: Is there an association between Helicobacter pylori infection and coronary heart disease? Eur J Epidemiol 15: 611-619, 1999.

39. Cholesterol, diastolic blood pressure, and stroke: 13,000 strokes in 450,000 people in 45 prospective cohorts. Prospective studies collaboration. Lancet 346: 1647-1653, 1995.

40. Parish S, Collins R, Peto R, Youngman L, Barton J, Jayne K, Clarke R, Appleby P, Lyon V, Cederholm-Williams S, et al: Cigarette smoking, tar yields, and non-fatal myocardial infarction: 14,000 cases and 32,000 controls in the United Kingdom. The international studies of infarct survival (ISIS) collaborators. BMJ 311: 471-477, 1995.

41. Lieb W and Vasan RS: Genetics of coronary artery disease. Circulation 128: 1131-1138, 2013

42. Lee JY, Lee BS, Shin DJ, Woo Park K, Shin YA, Joong Kim K, Heo L, Young Lee J, Kyoung Kim Y, Jin Kim Y, et al: A genome-wide association study of a coronary artery disease risk variant. J Hum Genet 58: 120-126, 2013.

43. Erbilgin A, Civelek M, Romanoski CE, Pan C, Hagopian R, Berliner JA and Lusis AJ: Identification of CAD candidate genes in GWAS loci and their expression in vascular cells. J Lipid Res 54: 1894-1905, 2013.

44. Schunkert H, König IR, Kathiresan S, Reilly MP, Assimes TL, Holm H, Preuss M, Stewart AF, Barbalic M, Gieger C, et al: Large-scale association analysis identifies 13 new susceptibility loci for coronary artery disease. Nat Genet 43: 333-338, 2011.

45. Mayerle J, den Hoed CM, Schurmann C, Stolk L, Homuth G, Peters MJ, Capelle LG, Zimmermann K, Rivadeneira F, Gruska S, et al: Identification of genetic loci associated with Helicobacter pylori serologic status. Jama 309: 1912-1920, 2013.

46. Maran S, Lee YY, Xu S, Rajab NS, Hasan N, Mustaffa N, Abdul Majid N and Bin Alwi Z: Deleted in colorectal cancer (DCC) gene polymorphism is associated with $H$.pylori infection among susceptible Malays from the north-eastern region of Peninsular Malaysia. Hepatogastroenterology 60: 124-128, 2013.

47. Kowalski M: Helicobacter pylori (H. pylori) infection in coronary artery disease: Influence of $H$. pylori eradication on coronary artery lumen after percutaneous transluminal coronary angioplasty. The detection of $H$. pylori specific DNA in human coronary atherosclerotic plaque. J Physiol Pharmacol 52 (1 Suppl 1): S3-S31, 2001.

48. Iriz E, Cirak MY, Engin ED, Zor MH, Erer D, Ozdogan ME, Turet S and Yener A: Detection of Helicobacter pylori DNA in aortic and left internal mammary artery biopsies. Tex Heart Inst J 35: 130-135, 2008

49. Hoffmeister A, Rothenbacher D, Bode G, Persson K, März W, Nauck MA, Brenner H, Hombach V and Koenig W: Current infection with Helicobacter pylori, but not seropositivity to Chlamydia pneumoniae or cytomegalovirus, is associated with an atherogenic, modified lipid profile. Arterioscler Thromb Vasc Biol 21: 427-432, 2001.

50. Vijayvergiya R and Vadivelu R: Role of Helicobacter pylori infection in pathogenesis of atherosclerosis. World J Cardiol 7: 134-143, 2015. 